\title{
BIOSYNTHESIS OF MYO-INOSITOL BY RAT TESTIS FOLLOWING SURGICALLY INDUCED CRYPTORCHIDISM OR TREATMENT WITH TRIETHYLENEMELAMINE
}

\author{
R. N. MORRIS* AND A. G. COLlinS $\dagger$ \\ Department of Pharmacology, School of Pharmacy, \\ University of Wisconsin, Madison, Wisconsin 53706, U.S.A.
}

(Received 16th November 1970)

\begin{abstract}
Summary. The biosynthesis of inositol from D-glucose was measured in testis slices from normal, cryptorchid and triethylenemelamine (TEM)-treated rats. A significant reduction of inositol synthetic activity accompanied the disappearance of spermatids and spermatozoa in both cryptorchid and TEM-treated animals. The onset of reduced inositol synthetic activity was extremely rapid in the cryptorchid testis, and preceded the appearance of grossly demonstrable histological alterations. These data suggest that de novo inositol synthesis might be required for maintenance of the cellular integrity of the germinal epithelium. This hypothesis is discussed in conjunction with recent theories concerning the rôle of inositol in the uptake of protein and nucleic acid precursors.
\end{abstract}

\section{INTRODUCTION}

Although the occurrence of inositol (in this paper, the term inositol is used as an abbreviation for myo-inositol or meso-inositol) in mammalian tissues has long been known, the presence of biosynthetic pathways for the synthesis of this compound in a variety of mammalian tissues suggests that the source of inositol is not totally exogenous (Halliday \& Anderson, 1955; Daughaday, Larner \& Hartnett, 1955). Mann (1951) and Hartree (1957) have shown mammalian seminal plasma to be one of the richest natural sources of free inositol. A comparison of inositol biosynthesis in homogenates of a number of rat tissues by Eisenberg \& Bolden (1963) revealed that the rat testis is approximately ten times as active as other tissues studied with respect to inositol biosynthesis. Separation of the interstitial cells from the seminiferous tubules by microdissection and subsequent assay of inositol synthesis revealed that activity resides primarily in the latter elements (Eisenberg, 1967). The seminal vesicles are known to concentrate and secrete inositol into seminal plasma (Melampy \& Mason, 1957), but little is known about the function of inositol in semen. The presence of a relatively active enzyme system for the synthesis of inositol in the

* Present address: Department of Pharmacology, College of Pharmacy, University of Nebraska, Lincoln, Nebraska 68508, U.S.A.

$\dagger$ Present address: Department of Pharmacology, University of Colorado Medical Center, Denver, Colorado 80220, U.S.A. 
seminiferous tubules suggests that de novo synthesis of this compound might reflect a metabolic requirement for the normal progression of spermatogenesis.

The present studies were undertaken in an effort to determine more exactly the cell types involved in testicular inositol synthesis. The techniques of artificially induced cryptochidism and triethylenemelamine (TEM) treatment were used to alter the cellular population of the rat testis before assay of inositol biosynthesis from $\mathbf{D}$-glucose in testis slice preparations.

\section{MATERIAL AND METHODS}

Animals

Male Holtzman rats, 55 to 60 days of age and weighing approximately $250 \mathrm{~g}$, were obtained from the Holtzman Company, Madison, Wisconsin. The animals were maintained on Rockland rat diet with unrestricted access.

\section{Treatment}

Rats were anaesthetized with sodium pentobarbital $(30 \mathrm{mg} / \mathrm{kg})$ supplemented with ether as required. A midline abdominal incision was made, and the testes were raised out of the scrotum by gently pulling the epididymal fat pad. A fine surgical suture was passed under the tunica albuginea. The testes were then secured to the musculature of the abdominal wall. The incision through the abdominal musculature was closed with wound clips. Care was taken to preserve intact the testicular circulation in order to minimize the possibility of ischaemia. Controls subjected to sham operation were treated similarly, but the testes were not secured to the abdominal wall, and could, therefore, re-descend.

Those animals treated with TEM (Pfaltz and Bauer, Flushing, New York) were given $0.2 \mathrm{mg} / \mathrm{kg}$ by intraperitoneal injection 6 days/week for up to 35 days. Saline-treated animals served as controls in this series of experiments.

\section{Incubations}

The animals were killed at various times after surgery or the initiation of TEM treatment by a blow on the head followed by decapitation. The testes were rapidly removed, the capsules excised, and tissue slices prepared with a Stadie-Riggs microtome at $4^{\circ} \mathrm{C}$. Approximately $400 \mathrm{mg}$ wet weight of testis were then placed in the main chamber of a Warburg flask containing $2.8 \mathrm{ml}$

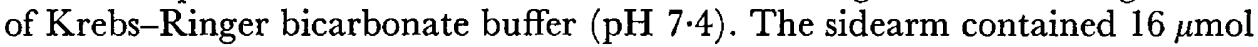
of D-glucose in $0.4 \mathrm{ml}$ to which $6 \times 10^{6} \mathrm{~d} / \mathrm{min}$ of $\left[\mathrm{U}^{14} \mathrm{C}\right] \mathrm{D}$-glucose had been added. The final concentration of D-glucose in the reaction chamber was $5 \mathrm{~mm}$. Radioactive D-glucose was obtained from the Amersham-Searle Corporation, and had a specific activity of $3.9 \mathrm{mCi} / \mathrm{mmol}$. After preincubation for $10 \mathrm{~min}$ under an atmosphere of $95 \% \mathrm{O}_{2}$ and $5 \% \mathrm{CO}_{2}$, the flasks were closed to the atmosphere and the sidearm contents added to the main chamber. The slices were incubated for varying periods of time at either 32 or $37.5^{\circ} \mathrm{C}$. The reactions were terminated by boiling the flask contents for $5 \mathrm{~min}$.

\section{Isolation of inositol}

Inositol was isolated by the method described by Eisenberg (1967). The 
boiled slices were homogenized and $100 \mathrm{mg}$ of unlabelled carrier inositol were added. The protein precipitate was then removed by centrifugation. The precipitates were washed twice with 3-ml aliquots of distilled water. The supernatants were pooled in a glass-stoppered bottle containing $500 \mathrm{mg} \mathrm{BaCO}_{3}$. In order to oxidize residual substrate, $1 \mathrm{ml}$ bromine was added to each vessel. This mixture was shaken vigorously for $30 \mathrm{~min}$. Excess bromine was removed by passing a stream of nitrogen through the mixture followed by the addition of drops of styrene. This suspension was then passed through a column of mixed bed ion exchange resin (Fisher Rexyn AG 501). The effluent, including $100 \mathrm{ml}$ of washings, was evaporated to about $1 \mathrm{ml}$. Ten vols of chilled methanol were added and re-crystallization of inositol was allowed to proceed at $4^{\circ} \mathrm{C}$. Inositol samples were recrystallized twice to ensure homogeneity which was shown by a constant specific activity. Inositol crystals were air dried, weighed and dissolved in water to exactly $1.0 \mathrm{ml}$. A $0 \cdot 1-\mathrm{ml}$ aliquot was added to $15 \mathrm{ml}$ Brays solution (Bray, 1960), and counted for $10 \mathrm{~min}$ on a Model 3002 Packard Tri-Carb liquid scintillation spectrometer. The degree of quenching was determined by addition of $\left[{ }^{14} \mathrm{C}\right]$ toluene internal standard. Counting efficiency ranged from 70 to $80 \%$.

The identity and purity of the isolated product were ascertained by cochromatography with authentic $\left[{ }^{14} \mathrm{C}\right]$ inositol on a $1 \times 21-\mathrm{cm}$ column of standard grade Whatman cellulose powder (Halliday \& Anderson, 1955). The column was eluted with acetone/water (8/2). The isolated inositol produced a single peak of radioactivity which coincided with that of authentic $\left[\mathrm{U}^{14} \mathrm{C}\right]$ inositol obtained from the Amersham-Searle Corporation.

\section{Histological preparations}

Samples of testis for histological preparations were taken from rats subjected to sham-operation, cryptorchidism, and TEM treatment. The tissues were fixed in Bouin's solution, dehydrated in alcohol, and cleared (Lillie, 1965). After embedding in paraffin wax, the tissues were stained with haematoxylin (Carlton \& Leach, 1947) and counterstained with eosin (Humason, 1967).

\section{RESULTS}

Complete spermatogenesis requires the lower ambient temperature provided by the scrotal position of the testes in most mammals (Moore, 1924). Metabolic studies by Davis, Firlit \& Hollinger (1963) have shown that the rate of incorporation of lysine into protein by rat testis slices in vitro is maximal at the scrotal temperature of $32^{\circ} \mathrm{C}$, while the normal rat body temperature of $37.5^{\circ} \mathrm{C}$ is optimal for liver, kidney and spleen. Similar data have been reported for other mammalian species (Buyer \& Davis, 1966).

Text-figure 1 illustrates the effect of scrotal versus body temperature on the rate of conversion of $\left[\mathrm{U}^{14} \mathrm{C}\right] \mathrm{D}$-glucose to inositol by rat testis slices. In the presence of 0.005 M-D-glucose, inositol synthesis was linear throughout the 60min incubation period at both temperatures. The rate of conversion at $37.5^{\circ} \mathrm{C}$ was 1.7 times that observed at $32^{\circ} \mathrm{C}$. Since the rate of testicular inositol synthesis was greater at $37.5^{\circ} \mathrm{C}$, this temperature was used for all succeeding incubations. 
Bilateral translocation of the testes to the abdominal cavity resulted in a rapid, $70 \%$ weight loss. Text-figure 2 shows the reduction in the testis weight. Day 0 represents the average testis weight of rats subjected to sham-operation.

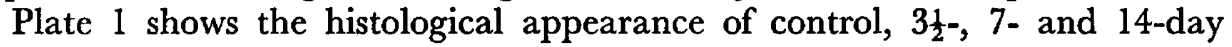
bilaterally cryptorchid testes. After 14 days, the cryptorchid testes have lost all of the cell types associated with normal spermatogenesis, with the exception of a few spermatogonia and Sertoli cells. The interstitial cells appear to be essentially unaltered. Between 0 and 7 days, the translocated testes undergo several histological changes. Within the first $3 \frac{1}{2}$ days, a considerable reduction in the number of spermatids and spermatozoa occurred. Simultaneously, the appearance of large, polynucleated cells was noted. Accompanying these changes was

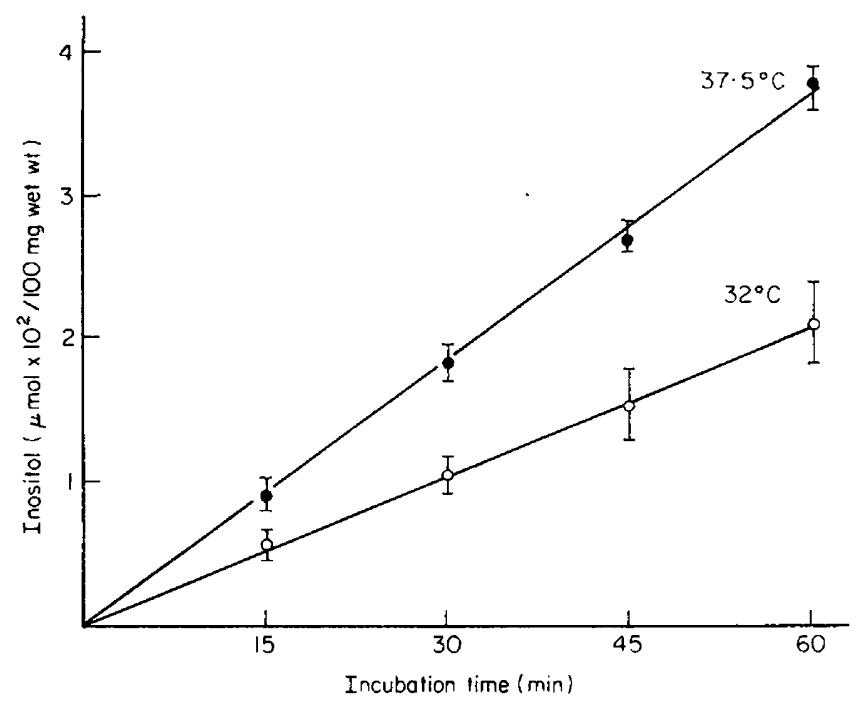

TEXT-FIG. 1. Conversion of D-glucose to inositol in rat testis slices incubated at $32^{\circ}$ and $37.5^{\circ}$ C. Flask contents: $5 \times 10^{-3} \mathrm{M}-\mathrm{D}-$ glucose containing $6 \times 10^{6} \mathrm{~d} / \mathrm{min}\left[\mathrm{U}-{ }^{14} \mathrm{C}\right] \mathrm{D}-$ glucose; Krebs-Ringer bicarbonate buffer, $\mathrm{pH} 7.4$, to a total volume of $3.2 \mathrm{ml}$; and $400 \mathrm{mg}$ wet weight testis slices. Gas phase was $95 \% \mathrm{O}_{2}$ and $5 \% \mathrm{CO}_{2}$. Each point on the curves for $32^{\circ}$ and $37.5^{\circ} \mathrm{C}$ represents eight and four experiments, respectively. Vertical lines indicate standard error of the mean for each point.

the presence of débris indicative of cellular necrosis. After 7 days, the number of identifiable spermatocytes was further reduced.

Text-figure 3 depicts the rate of inositol synthesis from $\left[\mathrm{U}^{14} \mathrm{C}\right] \mathrm{D}$-glucose in 14-day cryptorchid rat testis slices. The rate of synthesis was linear throughout the incubation period for both testis types. The rate of inositol synthesis by control (sham operation) testis slices was identical to that of the intact controls shown in Text-fig. 1. Cryptorchidism resulted in a $78 \%$ reduction in synthesis rate.

The decline in inositol synthesis resulting from cryptorchidism is illustrated in Text-fig. 4. The sham-operation control data are represented by the Day-0 bar. A progressive $78 \%$ decrease in inositol synthesis developed within the first 7 days, and remained constant throughout the remaining period of observation.

Plate 2 illustrates the effect of daily TEM administration on the histological 
PLATE 1

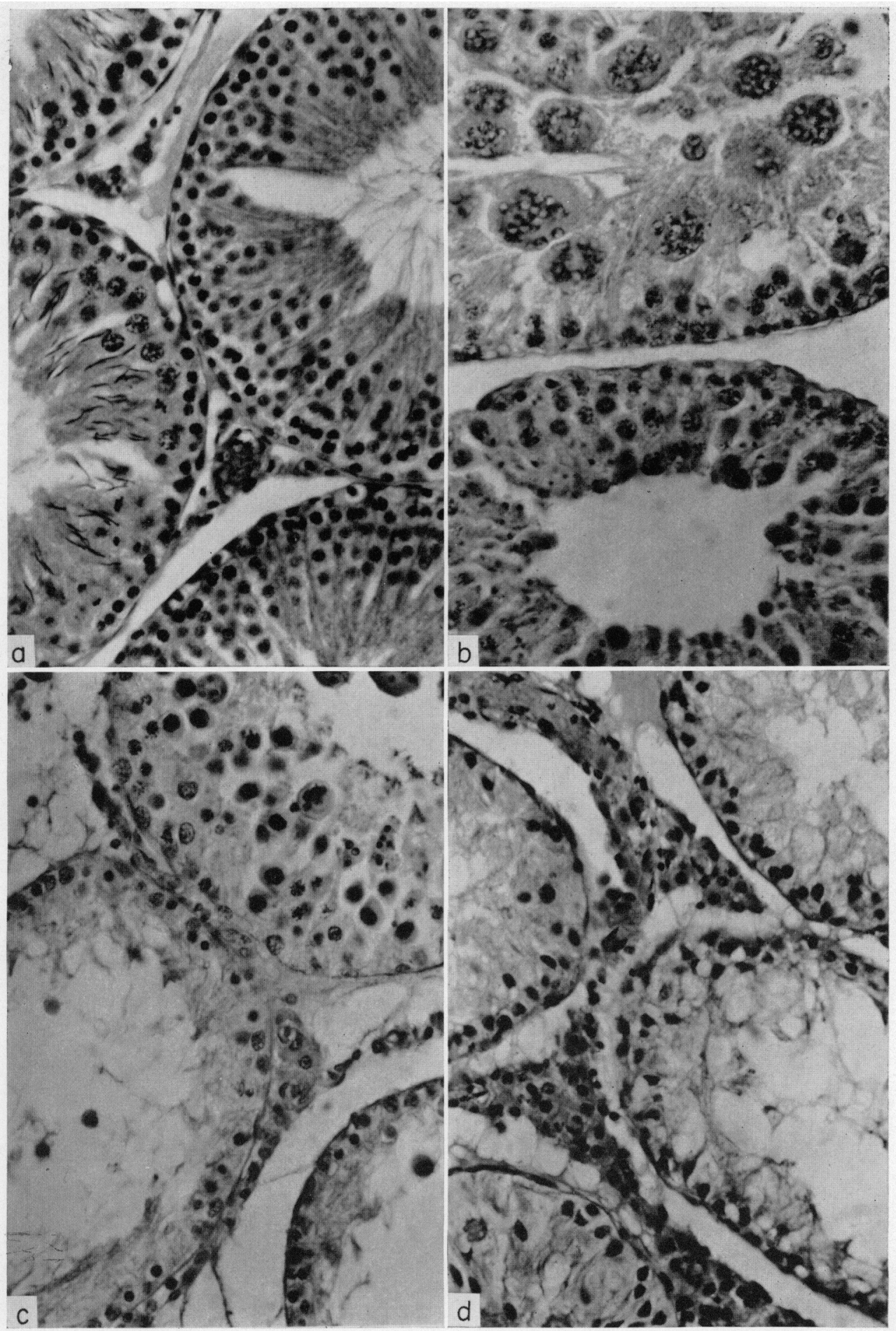

Histological appearance of control testis and cryptorchid testes at various times following surgical translocation: (a) sham operation control; (b) cryptorchid, 3.1 days; (c) cryptorchid, 7 days: (d) cryptorchid, 14 davs. Sections (10 $\mu \mathrm{m}$ thick) were stained with haematoxylin and counterstained with cosin. Magnification approximately $\times 350$. 
PI.ATE :

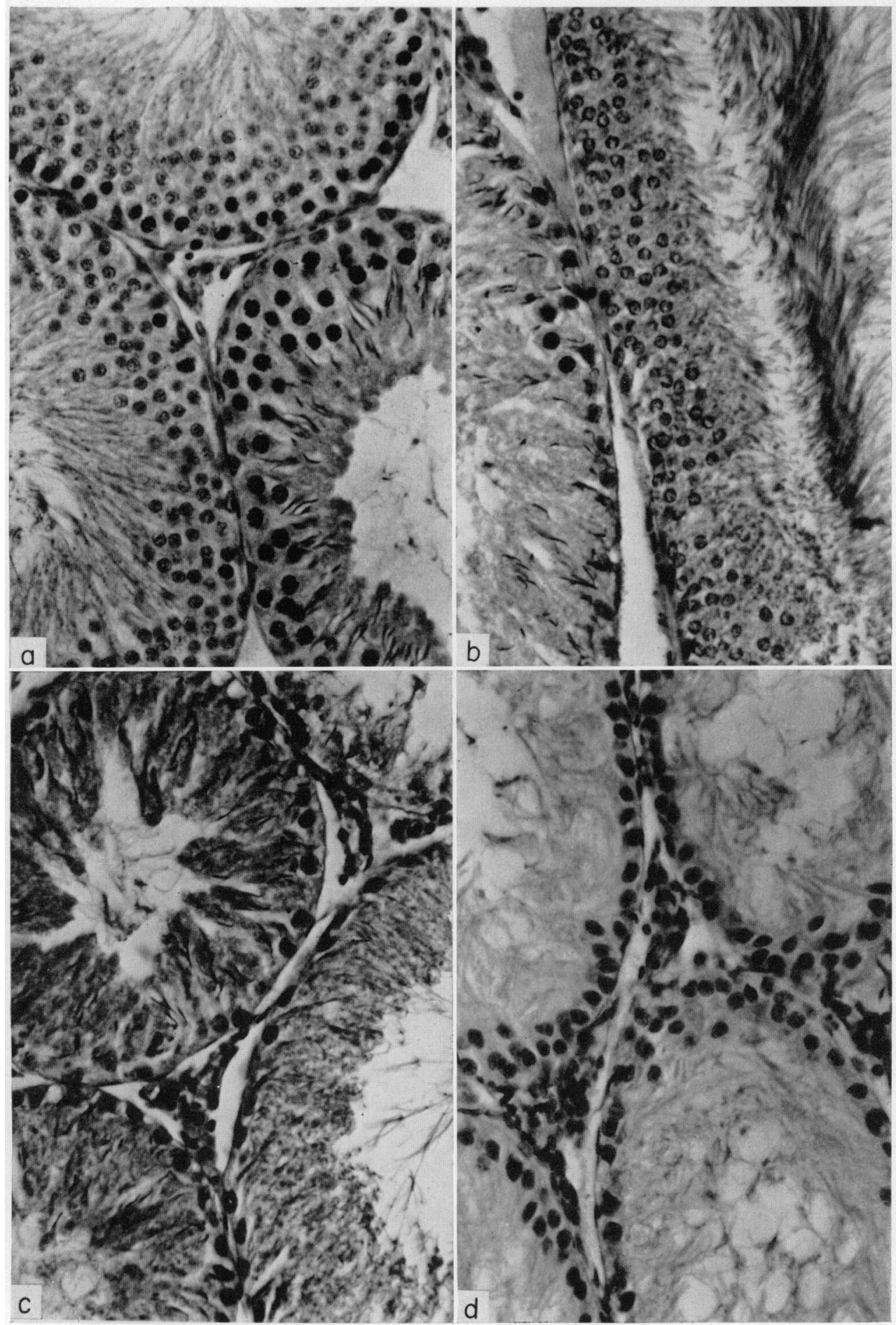

Histological appeanance of testes from animals treated with TEN (0.2 $\mathrm{mg} \mathrm{kg}$. 6 davs per werk): (a) 14 days; (b) 21 days; (c) 28 days; (d) 35 days. Soctions (10 $\mu$ m thick were staned with hacmatoxylin and countersained with essin. For control. see Pl. 1. Magnification approximatele $\times 330$. 


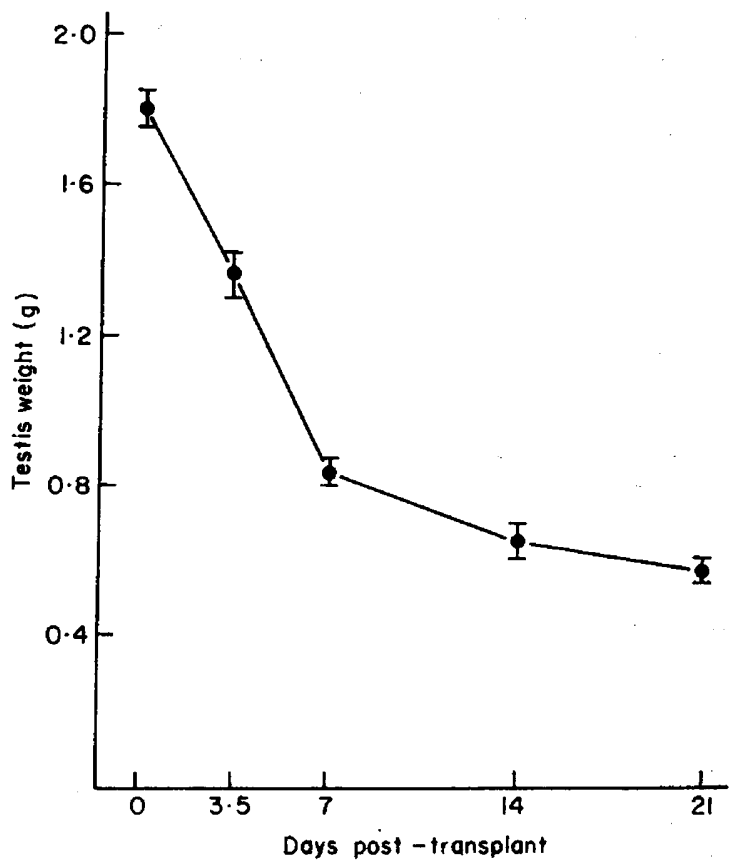

TExT-Fig. 2. Reduction in testis weight following surgically-induced cryptorchidism. At various times after surgery, testes were removed from bilaterally cryptorchid animals, and the testes weighed. Each point represents the average of twelve to twenty-two rats. Vertical lines represent standard error of the mean for each point.

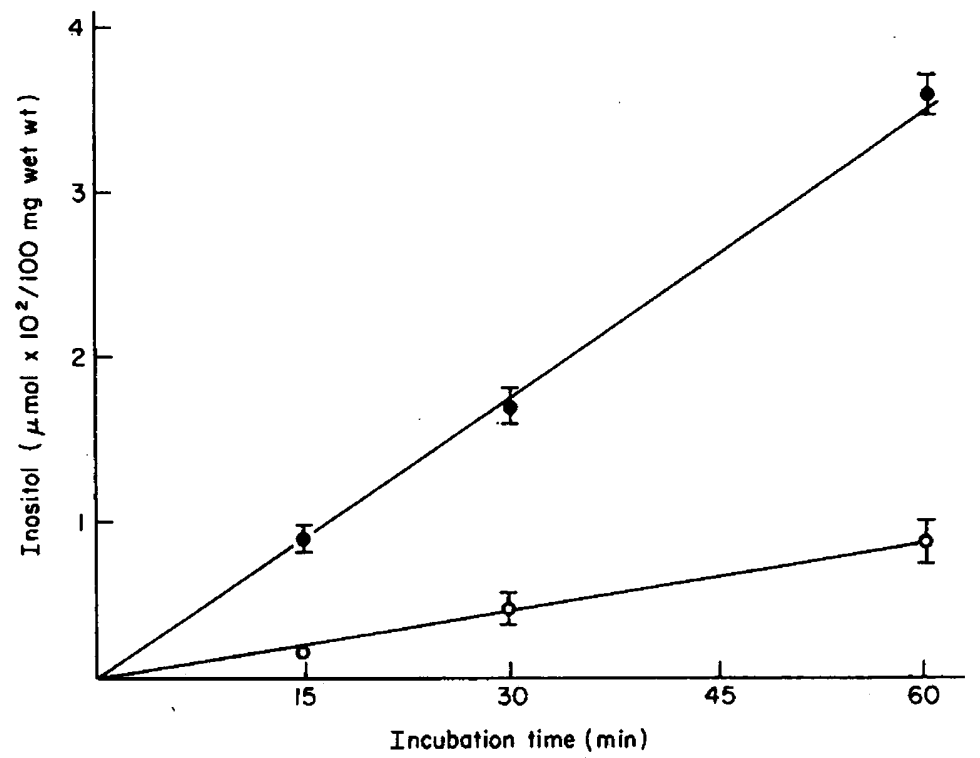

TExT-FIG. 3. Conversion of D-glucose to inositol by testis slices from sham operation (O) and 14-day bilaterally cryptorchid (O) rats. Incubation temperature was $37 \cdot 5^{\circ} \mathrm{C}$. Each point represents the mean of four to twelve experiments. For further details, see legend for Text-fig. 1 . 
appearance of the rat testis at 7 day intervals. The pattern of cellular damage is similar to that reported by Steinberger (1962). After 14 days of treatment, an almost total absence of spermatogonia was noted. The changes observed between 14 and 35 days were characteristic of maturation depletion. After 21 days, spermatids and spermatozoa constituted the major remaining cell types, but at the 28th day, very few spermatids were present, and spermatozoa predominated. After 35 days of treatment with TEM, Sertoli cells represented the major identifiable cell type.

Text-figure 5 demonstrates the effect of TEM on rat body and testis weights,

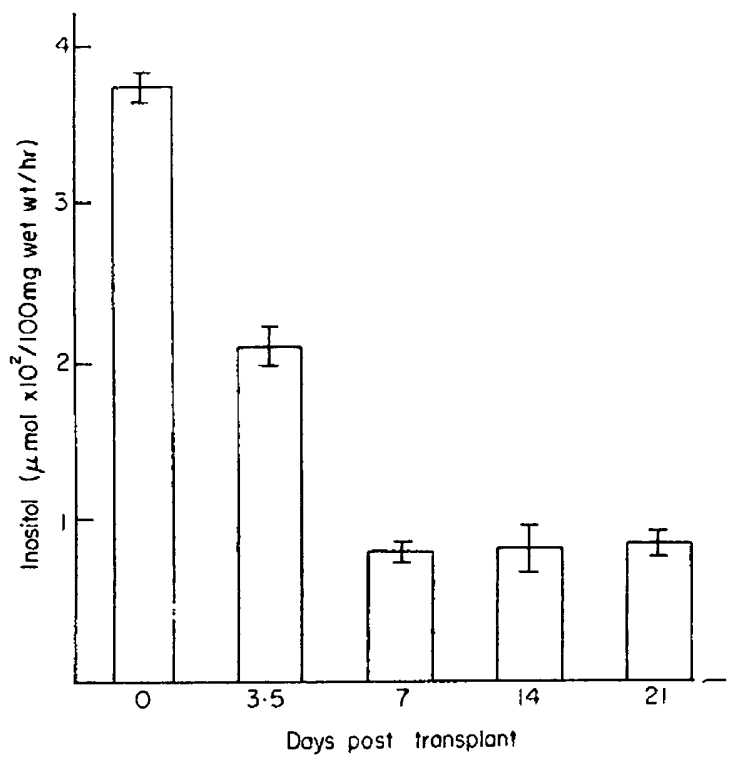

TEXT-FIG. 4. Effect of surgical cryptorchidism on the rate of conversion of D-glucose to inositol by rat testis slices at $37.5^{\circ} \mathrm{C}$. Testis slices were incubated at various times following induction of cryptorchidism. Each bar represents the average of five to twelve experiments. Vertical lines depict the standard error of the mean. For further details, see legend for Text-fig. 1 .

as well as on the ability of rat testis slices to synthesize inositol from D-glucose in vitro. All points on this graph represent data from three to six animals. Saline-treated control rats gained approximately $150 \mathrm{~g}$ body weight over the 35-day period, while TEM-treated animals lost about $80 \mathrm{~g}$. Simultaneously, the control testis weight increased by almost $200 \mathrm{mg}$, whereas an average $1250-\mathrm{mg}$ loss was noted in the testes of TEM-treated animals. The loss in testis weight was particularly obvious after the 14th day of TEM treatment.

The rates of inositol synthesis in testis slices from control and TEM-treated rats were nearly identical for the first 21 days of treatment. Between 21 and 35 days, a rapid, progressive decrease in activity occurred in the testis slices of the treated rats. At 28 and 35 days, 42 and $91 \%$ reductions in activity, respectively, were noted. 


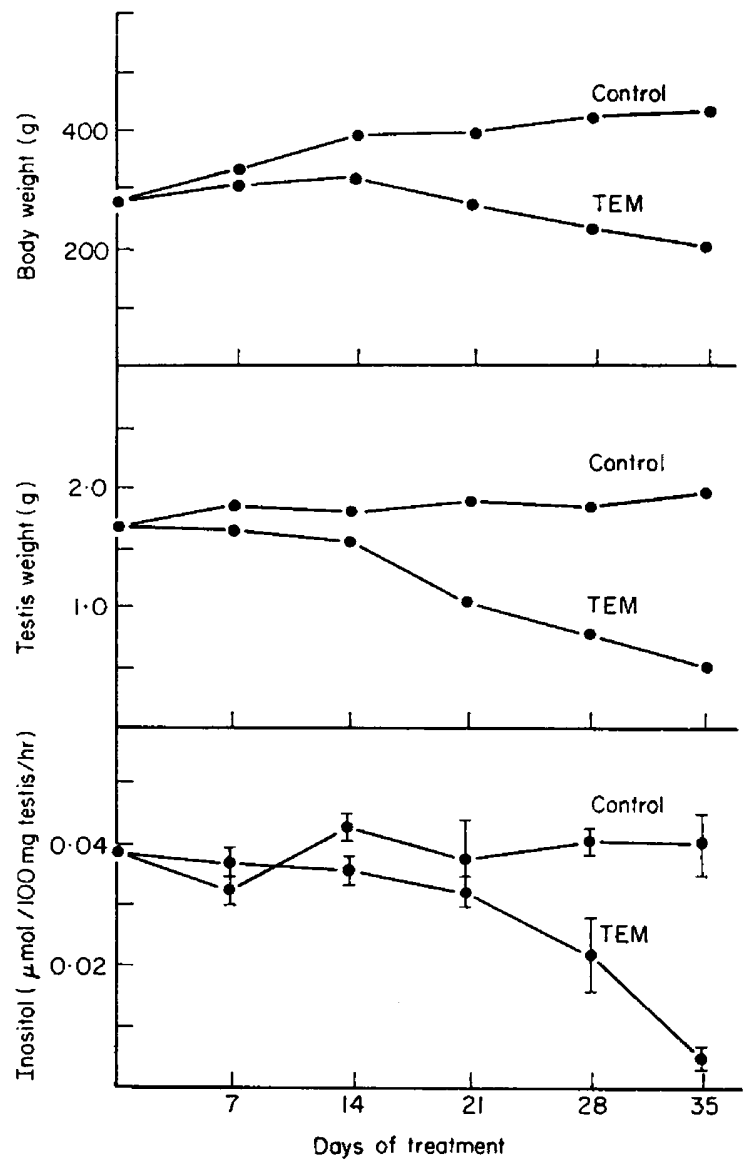

TeXT-FIG. 5. Effects of TEM administered in vivo on rat body weight, testis weight and rate of conversion of $\mathrm{D}$-glucose to inositol by testis slices. Rats were injected with TEM $(0.2 \mathrm{mg} / \mathrm{kg} / \mathrm{day}, 6$ days/week $)$, and killed at various times. The rate of inositol synthesis from D-glucose by testis slices from TEM-treated rats is shown in the bottom graph. Vertical lines indicate standard deviation of the mean. For complete incubation conditions, see text and legend for Text-fig. 1.

\section{DISCUSSION}

Translocation of the testes to the abdominal cavity and treatment with TEM constitute two means of altering the cellular population of the testis in a predictable manner. Artificial cryptorchidism results in a rapid loss of spermatozoa and spermatids (Niemi \& Kormano, 1965), while TEM administration causes an initial loss of type A spermatogonia followed by an orderly depletion of spermatocytes, spermatids and spermatozoa due to maturation (Steinberger, 1962).

Although Eisenberg (1967) has provided evidence suggesting that inositol biosynthesis is a function of the germinal epithelium, the exact cellular site has not been elucidated. The present study represents an attempt to correlate the level of inositol synthetic activity with the presence or absence of the various cell types which constitute the germinal epithelium. 
Following the induction of artificial cryptorchidism, a maximum depression in inositol synthesis developed between 0 and 7 days, and was sustained through 21 days (Text-fig. 4). Beyond Day 7, total loss of spermatids was apparent, and the depressed level of inositol synthetic activity remained stable despite the subsequent loss of spermatocytes.

Daily treatment with TEM resulted in evident depletion of spermatogonia by Day 14 (Plate 2). Between Days 21 and 35, spermatids and spermatozoa were depleted. Accompanying the disappearance of these later cell types was a significant, progressive decrease in inositol biosynthesis. These data, in conjunction with the cryptorchid studies, suggest that the majority of inositol synthetic activity resides in these more mature cell types. The capacity of these cells to synthesize inositol is apparently short-lived, since Eisenberg (1967) has shown that rat epididymal spermatozoa are incapable of converting glucose to inositol.

The presence of high inositol concentrations in seminal plasma coupled with the demonstrated capacity for inositol biosynthesis by the rat testis suggests the possibility that de novo synthesis by the testis might represent a source of seminal inositol. Stewart, Sherman \& Harris (1969) confirmed this possibility by demonstrating a $71 \%$ increase in the concentration of testicular inositol after ligation of the vasa efferentia. The seminal vesicle is known, however, to concentrate dietary inositol (Melampy \& Mason, 1957), and presumably contributes to the total concentration occurring in ejaculated semen. Thus, it is difficult to quantify the relative contributions of de novo synthesis and seminal vesicular secretion.

The possibility exists that inositol biosynthesis might be essential to the normal metabolism of the germinal epithelium. Agranoff, Bradley \& Brady (1958) have shown that the utilization of inositol by testis homogenates includes incorporation into lipids, while none is catabolized to glucuronic acid as in the kidney.

Studies of metabolic derangements in KB cells grown in an inositol-deficient medium suggest a possible metabolic function for inositol in mammalian tissues. Under these conditions, the synthesis of nucleic acid precursors and nucleic acids is decreased significantly (Charalampous, Wahl \& Ferguson, 1961; Tsukagoshi, Lembach \& Charalampous, 1966; Lembach \& Charalampous, 1966) and the uptake of amino acid precursors for protein and nucleic acid biosynthesis is similarly depressed (Lembach \& Charalampous, 1967a, b). The demand for DNA and RNA precursors might be especially great in the rapidly proliferating elements of the germinal epithelium and synthesis of inositol de novo might be required to maintain adequate intracellular levels of these precursors.

The fundamental biochemical alterations contributing to degenerative changes in the germinal epithelium accompanying cryptorchidism have not been elucidated. Elevation of the rates of protein and nucleic acid labelling (Davis, Morris \& Hollinger, 1964; Davis \& Firlit, 1965; Hollinger \& Davis, 1969) probably represents an 'unmasking' of the normal activity of the surviving cells, and requires several weeks for complete development. In contrast, the present studies indicate that inositol synthesis is greatly impaired within $3 \frac{1}{2}$ 
days of testicular translocation, and is maximally depressed within 7 days. The demonstrable histological changes observed within this time-span, however, are relatively minimal. These observations suggest the possibility that depression of inositol synthesis might precede cytological deterioration of the germinal epithelium, and that synthesis de novo might be essential to the maintenance of cellular integrity of the mature epithelial cell types. Experiments designed to assess the importance of metabolic factors regulating the synthesis and fate of inositol in rat testis preparations are in progress.

\section{ACKNOWLEDGMENTS}

This research was supported in part by grants from the U.S. Public Health Service (NIH, NIDR DE-171 and NIH, GRS FR-05456) and a grant provided by the Graduate School Research Committee, University of Wisconsin.

The authors wish to express their gratitude to Professor Laurens Anderson of the Department of Biochemistry for his encouragement and many helpful suggestions; and to Professor John W. Anderson of the Department of Anatomy for assistance in the preparation and interpretation of histological materials.

\section{REFERENGES}

Agranoff, B. W., Bradley, R. M. \& Brady, R. O. (1958) The enzymatic synthesis of inositol phosphatide. F. biol. Chem. 233, 1077.

Brax, G. A. (1960) A simple efficient liquid scintillator for counting aqueous solutions in a liquid scintillation counter. Analyt. Biochem. 1, 279.

BuYer, R. \& DAvis, J. R. (1966) Species variation in the effect of temperature on the incorporation of 1-lysine-U-C ${ }^{14}$ into protein of testis slices. Comp. Biochem. Physiol. 17, 151.

Gartton, H. M. \& Leach, E. H. (1947) Histological technique, p. 84. Oxford University Press, New York.

Charalampous, F. G., Wahl, M. \& Ferguson, L. (1961) Metabolic functions of myo-inositol. II. Effect of inositol deficiency on the metabolism of nucleic acids of mammalian cells in tissue culture. 7. biol. Chem. 236, 2552.

Daughaday, W. H., Larner, J. \& Hartnett, C. (1955) The synthesis of inositol in the immature rat and chick embryo. 7 . biol. Chem. 212, 869.

Davis, J. R. \& FiRLIT, C. F. (1965) Effect of glucose on uptake of $1-1 y s i n e-\mathrm{H}^{3}$ in cells of the seminiferous epithelium. Am. 7. Physiol. 209, 425.

Davis, J. R., Firlit, G. F. \& Hollinger, M. A. (1963) Effect of temperature on incorporation of 1-lysine-U-G ${ }^{14}$ into testicular proteins. Am. F. Physiol. 204, 696.

Davis, J. R., Morris, R. N. \& Hollinger, M. A. (1964) Incorporation of 1-lysine-U-C ${ }^{14}$ into proteins of cryptorchid testis slices. Am. 7. Physiol. 207, 50.

EIsENBERG, F. (1967) D-Myo-inositol-1-phosphate as product of cyclization of glucose-6-phosphate and substrate for a specific phosphatase in rat testis. 7. biol. Chem. 242, 1375.

Eisengerg, F. \& Bolden, A. H. (1963) Biosynthesis of inositol in rat testis homogenate. Biochem. biophys. Res. Commun. 12, 72.

Halliday, J. W. \& ANDERson, L. (1955) The synthesis of myo-inositol in the rat. F. biol. Chem. 217, 797.

Hartree, E. F. (1957) Inositol in seminal plasma. Biochem. F. 66, 131.

Hold.nger, M. A. \& DAvis, J. R. (1969) Nucleic acid labelling of experimentally-induced cryptorchid rat testis. F. Reprod. Fert. 18, 325.

Humason, G. L. (1967) Animal tissue techniques, p. 137. Freeman, San Francisco.

Lembach, K. \& Gharalampous, F. G. (1966) Metabolic functions of myo-inositol. IV. Temporal changes of the level of various enzyme activities during development of inositol deficiency. 7. biol. Chem. 241, 395.

Lembach, K. \& Gharalampous, F. G. (1967a) Metabolic functions of myo-inositol. V. Utilization of glycine and serine in nucleotide and nucleic acid biosynthesis by inositol-deficient $\mathrm{KB}$ cells. 7. biol. Chem. 242, 2599.

Lembach, K. \& Gharalampous, F. C. (1967b) Metabolic functions of myo-inositol. VI. Impairment of amino acid transport in KB cells caused by inositol deficiency. 7. biol. Chem. 242, 2606.

LILlIE, R. D. (1965) Histopathologic technic and practical histochemistry, p. 72. McGraw-Hill, New York. 
MANN, T. (1951) Inositol. A major constituent of the seminal vesicle secretion of the boar. Nature, Lond. 168, 1043.

Melampy, R. M. \& Mason, R. B. (1957) Androgen and the myo-inositol content of male accessory organs of the rat. Proc. Soc. exp. Biol. Med. 96, 405.

MOORE, C. R. (1924) Properties of the gonads as controllers of somatic and psychical characteristics. VI. Testicular reactions in experimental cryptorchidism. Am. F. Anat. 34, 269.

Niemi, M. \& Kormano, M. (1965) Response of the cycle of the seminiferous epithelium of the rat testis to artificial cryptorchidism. Fert. Steril. 16, 236.

StEINBERGER, E. (1962) A quantitative study of the effect of an alkylating agent (triethylene melamine) on the seminiferous epithelium of rats. 7. Reprod. Fert. 3, 250.

Stewart, M. A., Sherman, W. R. \& Harris, J. T. (1969) Effects of galactose on levels of free myoinositol in rat tissues. Ann. N.Y. Acad. Sci. 165, 609.

Tsukagoshi, S., Lembach, K. \& Charalampous, F. G. (1966) Metabolic functions of myo-inositol. III. Utilization of purine bases and nucleosides for nucleic acid biosynthesis in inositol-deficient KB cells. F. biol. Chem. 241, 388. 